\title{
Triple-Nucleoside Regimens versus Efavirenz-Containing Regimens for the Initial Treatment of HIV-1 Infection
}

\author{
Roy M. Gulick, M.D., M.P.H., Heather J. Ribaudo, Ph.D., \\ Cecilia M. Shikuma, M.D., Stephanie Lustgarten, M.S., Kathleen E. Squires, M.D., \\ William A. Meyer III, Ph.D., Edward P. Acosta, Pharm.D., \\ Bruce R. Schackman, Ph.D., Christopher D. Pilcher, M.D., Robert L. Murphy, M.D., \\ William E. Maher, M.D., Mallory D. Witt, M.D., Richard C. Reichman, M.D., \\ Sally Snyder, B.S., Karin L. Klingman, M.D., and Daniel R. Kuritzkes, M.D., \\ for the AIDS Clinical Trials Group Study A5095 Team**
}

ABSTRACT

From the Weill Medical College of Cornell University, New York (R.M.G., B.R.S.); the Statistical and Data Analysis Center, Harvard School of Public Health, Boston (H.J.R., S.L.); the University of Hawaii, Honolulu (C.M.S.); the University of Southern California Medical Center, Los Angeles (K.E.S.); Quest Diagnostics, Baltimore (W.A.M.); the University of Alabama at Birmingham, Birmingham (E.P.A.); the University of North Carolina at Chapel Hill, Chapel Hill (C.D.P.) Northwestern University, Chicago (R.L.M.); Ohio State University, Columbus (W.E.M.) the Harbor-UCLA Medical Center, Los Angeles (M.D.W.); the University of Rochester Medical Center, Rochester, N.Y. (R.C.R.); Social and Scientific Systems, Silver Spring Md. (S.S.); the Division of AIDS, Nationa Institute of Allergy and Infectious Disease, Bethesda, Md. (K.L.K.); and Brigham and Women's Hospital and Harvard Medical School, Boston (D.R.K.). Address reprin requests to Dr. Gulick at the Cornell Clinical Trials Unit, Box 566, 525 E. 68th St. New York, NY 10021, or at rgulick@med. cornell.edu.

*Other members of the AIDS Clinical Trials Group (ACTG) Study A5095 Team are listed in the Appendix.

N EnglJ Med 2004;350:1850-61.

Copyright @ 2004 Massachusetts Medical Society.
BACK GROUN D

Regimens containing three nucleoside reverse-transcriptase inhibitors offer an alternative to regimens containing nonnucleoside reverse-transcriptase inhibitors or protease inhibitors for the initial treatment of human immunodeficiency virus type 1 (HIV-1) infection, but data from direct comparisons are limited.

\section{METHODS}

This randomized, double-blind study involved three antiretroviral regimens for the initial treatment of subjects infected with HIV-1: zidovudine-lamivudine-abacavir, zidovudine-lamivudine plus efavirenz, and zidovudine-lamivudine-abacavir plus efavirenz.

\section{RESULTS}

We enrolled a total of 1147 subjects with a mean baseline HIV-1 RNA level of $4.85 \log _{10}$ $(71,434)$ copies per milliliter and a mean CD4 cell count of 238 per cubic millimeter were enrolled. A scheduled review by the data and safety monitoring board with the use of prespecified stopping boundaries led to a recommendation to stop the triple-nucleoside group and to present the results in the triple-nucleoside group in comparison with pooled data from the efavirenz groups. After a median follow-up of 32 weeks, 82 of 382 subjects in the triple-nucleoside group (21 percent) and 85 of 765 of those in the combined efavirenz groups (11 percent) had virologic failure; the time to virologic failure was significantly shorter in the triple-nucleoside group $(\mathrm{P}<0.001)$. This difference was observed regardless of the pretreatment HIV-1 RNA stratum (at least 100,000 copies per milliliter or below this level; $\mathrm{P} \leq 0.001$ for both comparisons). Changes in the CD4 cell count and the incidence of grade 3 or grade 4 adverse events did not differ significantly between the groups.

\section{CONCLUSIONS}

In this trial of the initial treatment of HIV-1 infection, the triple-nucleoside combination of abacavir, zidovudine, and lamivudine was virologically inferior to a regimen containing efavirenz and two or three nucleosides. 
NTIRETROVIRAL THERAPY FOR HUMAN immunodeficiency virus type 1 (HIV-1) in-

fection decreases viremia, increases CD4 cell counts, and delays clinical progression and death. ${ }^{1-5}$ Current treatment guidelines recommend initial therapy with one or more protease inhibitors or a nonnucleoside reverse-transcriptase inhibitor together with two nucleoside reverse-transcriptase inhibitors. ${ }^{6,7}$ Though effective, protease-inhibitor-based regimens are complex and have been associated with side effects such as hyperlipidemia and insulin resistance. ${ }^{8-10}$ Regimens containing nonnucleoside reverse-transcriptase inhibitors are often preferred because of their demonstrated efficacy ${ }^{11-13}$ and convenience. ${ }^{14}$

Triple-nucleoside regimens are an alternative to regimens containing nonnucleoside reverse-transcriptase inhibitors or protease inhibitors. ${ }^{6,7}$ Triple-nucleoside combinations have potent antiretroviral activity ${ }^{15-17}$ with efficacy similar to that of regimens containing indinavir or nelfinavir. ${ }^{18-20}$ Triple-nucleoside regimens are among the simplest for patients to take and are used widely. ${ }^{6,7}$

We performed a direct comparison of three simple, protease-inhibitor-sparing regimens for the initial treatment of HIV-1 infection: a triple-nucleoside regimen, a nonnucleoside reverse-transcriptase inhibitor combined with two nucleosides, and a nonnucleoside reverse-transcriptase inhibitor combined with three nucleosides.

\section{METHODS}

\section{STUDY SUBJECTS}

Eligible patients were HIV-1-infected adults who had received no previous antiretroviral therapy and who had a plasma HIV-1 RNA level of at least 400 copies per milliliter (HIV-1 Monitor Assay, version 1.0, Roche Molecular Systems). Patients were excluded if they had received immunomodulator or investigational therapy or vaccines within the previous 30 days, if they weighed less than $40 \mathrm{~kg}$, or if they were pregnant or breast-feeding.

\section{STUDY DESIGN}

We conducted a randomized, double-blind, placebo-controlled comparison of three antiretroviral regimens for the initial treatment of HIV-1 infection. Subjects were stratified at randomization according to their HIV-1 RNA level at screening (at least 100,000 copies per milliliter or fewer than 100,000 copies per milliliter). The planned dura- tion of the study was 96 weeks from the enrollment of the last subject. The study was approved by the institutional review board of each participating site, and all subjects gave written informed consent. Screening evaluations included a review of the HIV treatment history and documentation of HIV-1 serologic analysis and the plasma HIV-1 RNA level within 90 days before study entry. The baseline evaluations included a medical history, a clinical assessment, laboratory tests, measurement of plasma HIV-1 RNA, and a CD4 cell count. In addition, a plasma sample was obtained at base line and stored for later HIV-1 genotyping.

Eligible subjects were assigned with equal probability to one of three study regimens (including placebos for blinding as necessary) given orally at standard doses and intervals: zidovudine-lamivudine-abacavir (Trizivir, GlaxoSmithKline), zidovudine-lamivudine (Combivir, GlaxoSmithKline) plus efavirenz (Sustiva, Bristol-Myers Squibb), or zidovudine-lamivudine-abacavir plus efavirenz. Subjects took a total of seven pills per day (including placebos), divided into two doses. In the event of toxic effects of the study drugs that were considered by the site investigator to be treatment-limiting, the identity of the implicated drug was allowed to be revealed and substitution of another drug in the same class was permitted. Stavudine (Zerit, Bristol-Myers Squibb) could be substituted for zidovudine, didanosine (Videx EC, Bristol-Myers Squibb) could be substituted for abacavir, and nevirapine (Viramune, Boehringer Ingelheim) could be substituted for efavirenz.

Subjects were evaluated at weeks 2 and 4, then every four weeks until week 24 , and every eight weeks thereafter. Each visit included clinical and laboratory assessments and the measurement of plasma HIV-1 RNA. In addition, CD4 cell counts were performed at weeks 4 and 8 and every 8 weeks thereafter, a lipid panel was obtained every 16 weeks, and a pregnancy test was performed whenever pregnancy was suspected. A questionnaire about adherence to the study regimen was administered at weeks 4,12 , and 24 and every 24 weeks thereafter. For subjects who permanently discontinued the study treatment, laboratory tests, HIV-1 RNA measurements, and CD4 cell counts were performed every eight weeks.

Virologic failure was defined by two successive HIV-1 RNA values of 200 or more copies per milliliter at least 16 weeks after randomization; the date of virologic failure was recorded as the date when 
the first such value was obtained. Suspected virologic failure was to be confirmed within four weeks. After confirmed virologic failure, the treatmentgroup assignment could be revealed. Genotypic resistance testing (TruGene, version 6.0, Visible Genetics) was performed on both the specimen used to confirm failure (if the HIV-1 RNA level was at least 500 copies per milliliter) and the stored baseline specimen, and the results of both tests were reported. If the HIV-1 RNA level was between 200 and 9999 copies per milliliter, the subject could continue to receive the assigned regimen or switch to a second study-provided regimen. Subjects with either a confirmed HIV-1 RNA level of at least 10,000 copies per milliliter or continued treatment-limiting toxic effects despite the substitution of one or more of the alternative drugs proceeded to a second regimen. Adverse events were assessed by the site investigators and were graded according to the toxicity scale of the Division of AIDS, National Institutes of Health.

\section{STATISTICAL ANALYSIS}

The objectives of the study were to compare the three regimens in terms of safety, tolerability, and virologic efficacy. The study was designed to have 86 percent power to show a noninferior rate of virologic failure with the triple-nucleoside regimen as compared with zidovudine-lamivudine and efavirenz if the failure rates for the two regimens were the same (defined by a hazard ratio for virologic failure with an upper 95 percent confidence limit of less than 1.35) and to have 80 percent power to detect a ratio hazard for virologic failure of 0.70 for the other pairwise comparisons. With adjustment for interim analyses and loss to follow-up, it was determined that a sample of 375 subjects per group would be needed.

Base-line HIV-1 RNA levels were calculated as the geometric mean of two measurements obtained before therapy began. Analyses of time to virologic failure were performed according to the KaplanMeier method and with the use of log-rank tests and Cox proportional-hazards models stratified according to the HIV-1 RNA level at screening. ${ }^{21}$ Changes in the CD4 cell count over time were compared with the use of the methods of Wei and Johnson. ${ }^{22}$ Adherence to the study regimen was calculated as the ratio of the number of doses taken to the number prescribed over a four-day period, and comparisons of adherence were made with the use of a Cochran-Mantel-Haenzsel test. ${ }^{23}$ The associ- ation between adherence and virologic failure was assessed by means of a Cox proportional-hazards model stratified according to the treatment group.

Analyses of all efficacy variables were performed on an intention-to-treat basis and included all follow-up data, including data obtained after the discontinuation of treatment or virologic failure, from all randomized subjects to whom study drugs were dispensed. Data were censored at the time of withdrawal from the study, and missing evaluations were ignored. For analyses of adverse events, follow-up data were censored either 56 days after the permanent discontinuation of treatment or at the time of withdrawal from the study, whichever came first. All reported P values are two-sided; P values and confidence intervals are unadjusted for interim analyses.

The study was reviewed annually for safety and efficacy by the data and safety monitoring board of the National Institute of Allergy and Infectious Diseases. At each review, the method of O'Brien and Fleming ${ }^{24}$ was used to compare each three-drug regimen with the four-drug regimen; a Lan-DeMets spending function ${ }^{25}$ was used to protect the type I error rate for sequential monitoring. For the noninferiority comparison of the triple-nucleoside group with the two groups receiving nucleosides plus efavirenz, the adjustment method of Peto et al. ${ }^{26}$ was used so that at each interim analysis, consideration was given to modifying the trial design because of sufficient evidence to declare noninferiority if the upper 99.9 percent confidence limit for the hazard ratio for virologic failure was less than 1.35.

Because of the possibility that the triple-nucleoside regimen could be inferior to the two nucleosides plus efavirenz, stopping guidelines were specified that evaluated the accumulated evidence in the light of the alternative hypothesis. ${ }^{27}$ Specifically, if the lower 95 percent confidence limit of the hazard ratio for virologic failure was greater than 1.14 , it was recommended that the study design be changed on the grounds that noninferiority could not be demonstrated. This stopping rule involves the use of the method of Pocock ${ }^{28}$ dividing the type II error rate (beta $=0.14$ ) equally among three planned interim analyses. Given the assumptions behind the sample-size calculation and the assumption of equal numbers of person-years of follow-up in all the study groups, the 1.14 boundary is the limit of the point estimate for the hazard ratio that would lead to the rejection of the null hypothesis at the final analysis (i.e., an upper 95 percent confidence limit 
of less than 1.35). If the accumulated data at any interim review were to be inconsistent with such a result, it is unlikely that we would ever be able to reject the null hypothesis.

At the second annual review in February 2003, with the use of data through November 2002, pairwise comparisons among the three study groups showed differences between the triple-nucleoside regimen and each of the efavirenz-containing regimens that met prespecified stopping guidelines (a lower 95 percent confidence limit of more than 1.14 for the noninferiority comparison and a boundary $P$ value of 0.003 for the comparison between the triple-nucleoside regimen and the four-drug regimen). The data and safety monitoring board recommended stopping the triple-nucleoside portion

\begin{tabular}{|c|c|c|}
\hline Characteristic & $\begin{array}{l}\text { Triple-Nucleoside } \\
\text { Group ( }=382 \text { ) }\end{array}$ & $\begin{array}{c}\text { Combined Efavirenz } \\
\text { Groups }(\mathrm{N}=765)\end{array}$ \\
\hline $\begin{array}{l}\text { Sex - no. (\%) } \\
\text { Male } \\
\text { Female }\end{array}$ & $\begin{array}{r}309(81) \\
73(19)\end{array}$ & $\begin{array}{l}620(81) \\
145(19)\end{array}$ \\
\hline $\begin{array}{l}\text { Age }-\mathrm{yr} \\
<20 \mathrm{Yr}-\text { no. }(\%) \\
\begin{array}{l}20-29 \mathrm{Yr}-\text { no. }(\%) \\
30-39 \mathrm{Yr}-\text { no. }(\%) \\
40-49 \mathrm{Yr}-\text { no. }(\%) \\
50-59 \mathrm{Yr}-\text { no. }(\%) \\
60-69 \mathrm{Yr}-\text { no. }(\%) \\
\geq 70 \mathrm{Yr}-\text { no. }(\%)\end{array}\end{array}$ & $\begin{array}{l}38.0 \pm 9.0 \\
8(2) \\
56(15) \\
162(42) \\
115(30) \\
37(10) \\
4(1) \\
0\end{array}$ & $\begin{array}{l}38.0 \pm 9.0 \\
14(2) \\
135(18) \\
307(40) \\
232(30) \\
60(8) \\
15(2) \\
2(<1)\end{array}$ \\
\hline $\begin{array}{l}\text { Race or ethnic group — no. (\%) } † \\
\text { Non-Hispanic white } \\
\text { Non-Hispanic black } \\
\text { Hispanic } \\
\text { Asian } \\
\text { American Indian } \\
\text { Other or unknown }\end{array}$ & $\begin{array}{l}150(39) \\
142(37) \\
82(21) \\
5(1) \\
3(1) \\
0\end{array}$ & $\begin{aligned} 314 & (41) \\
272 & (36) \\
163 & (21) \\
11 & (1) \\
3 & (<1) \\
2 & (<1)\end{aligned}$ \\
\hline $\begin{array}{l}\text { Intravenous drug use - no. (\%) } \\
\text { None ever } \\
\text { Current } \\
\text { Previous }\end{array}$ & $\begin{array}{c}340(89) \\
0 \\
42(11)\end{array}$ & $\begin{array}{r}682(89) \\
1(<1) \\
82(11)\end{array}$ \\
\hline Weight — lb & $138 \pm 53$ & $139 \pm 56$ \\
\hline $\begin{array}{l}\text { Screening HIV-1 RNA level — no. (\%) } \\
\quad<100,000 \text { copies } / \mathrm{ml} \\
\quad \geq 100,000 \text { copies } / \mathrm{ml}\end{array}$ & $\begin{array}{l}218(57) \\
164(43)\end{array}$ & $\begin{array}{l}437(57) \\
328(43)\end{array}$ \\
\hline 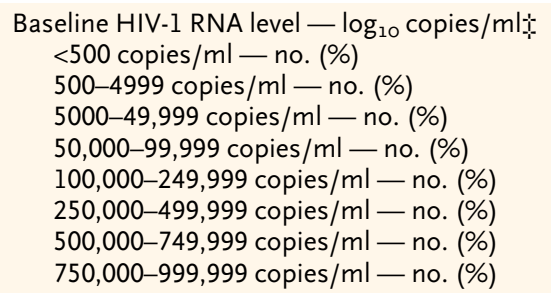 & $\begin{array}{l}4.85 \pm 0.70 \\
0 \\
16(4) \\
150(39) \\
54(14) \\
72(19) \\
65(17) \\
14(4) \\
11(3)\end{array}$ & $\begin{array}{l}4.86 \pm 0.73 \\
4(1) \\
32(4) \\
299(39) \\
111(15) \\
110(14) \\
138(18) \\
48(6) \\
23(3)\end{array}$ \\
\hline $\begin{array}{l}\text { Baseline CD4 cell count - cells } / \mathrm{mm}^{3} \int \\
0-50-\text { no. }(\%) \\
51-200-\text { no. }(\%) \\
201-500-\text { no. }(\%) \\
>500-\text { no. }(\%)\end{array}$ & $\begin{array}{r}234 \pm 187 \\
63(17) \\
127(33) \\
157(41) \\
34(9)\end{array}$ & $\begin{array}{l}242 \pm 193 \\
155(20) \\
203(27) \\
335(44) \\
72(9)\end{array}$ \\
\hline
\end{tabular}

* Plus-minus values are means \pm SD. To convert values for weight to kilograms, multiply by 0.45 .

$\dagger$ Race or ethnic group was self-reported by the subjects.

The baseline HIV-1 RNA level was calculated as the geometric mean of two measurements obtained before therapy began and within 30 days before study entry.

$\int$ The baseline CD4 cell count was calculated as the mean of two measurements obtained before therapy began and within 30 days before study entry. Data were missing for one subject. 
of the study, continuing double-blind follow-up of the other two groups, and analyzing and presenting the results with the data for the triple-nucleoside group compared with the pooled data from the efavirenz groups. Data through November 2002 are presented here.

\section{RESULTS}

\section{STUDY SUBJECTS}

A total of 1147 subjects enrolled in the study between March 2001 and November 2002; 1 subject inadvertently enrolled twice but was counted only once. A total of 81 percent of the study subjects were men, and 60 percent were nonwhite; 11 percent had used intravenous drugs (Table 1). The mean baseline HIV-1 RNA level was $4.85 \log _{10}(71,434)$ copies per milliliter; 43 percent of the subjects had an HIV-1 RNA level of 100,000 or more copies per milliliter. The mean baseline CD4 cell count was 238 per cubic millimeter. The treatment groups were balanced in terms of baseline characteristics.

\section{DISPOSITION OF THE SUBJECTS}

After a median follow-up of 32 weeks (range, 0 to 80), 1064 subjects (93 percent) remained in the study and follow-up was discontinued in 83 subjects ( 7 percent) for various reasons: the withdrawal of consent (in 21 cases), loss to follow-up (in 21 cases), inability to attend visits (in 19 cases), nonadherence to the study regimen (in 11 cases), severe debilitation (in 4 cases), and death - from HIV-1-related illness (in 2 cases), metastatic carcinoma (in 1 case), probable zidovudine-related hepatitis (in 1 case), accident (in 1 case), and unknown causes (in 2 cases). There were no significant differences in the rates of discontinuation between the treatment groups. In all, 1136 subjects (99 percent) received the study treatment to which they were assigned, and 11 subjects ( 1 percent) never started the study treatment. A total of 940 subjects ( 82 percent) continued to receive their initial study regimen (with or without substitutions because of treatment-limiting toxic effects), 32 (3 percent) proceeded to a second study regimen, and 81 (7 percent) permanently discontinued study treatment but continued to be followed.

\section{HIV-I RNA LEVEL AND CD4 CELL COUNT}

Protocol-defined virologic failure occurred in 167 subjects: 82 of the 382 in the triple-nucleoside group (21 percent) and 85 of the 765 in the combined efa- virenz groups (11 percent). The time to virologic failure was significantly shorter in the triple-nucleoside group than in the combined efavirenz groups $(\mathrm{P}<0.001)$ (Fig. 1A). Significant differences were also observed in analyses of the subgroup with a pretreatment HIV-1 RNA level below 100,000 copies per milliliter $(\mathrm{P}=0.001)$ (Fig. 1B) and the subgroup with a pretreatment level of 100,000 copies per milliliter or higher $(\mathrm{P}<0.001)$ (Fig. 1C) and in post hoc analyses of the subgroup with a pretreatment CD4 count of 100 cells per cubic millimeter or higher $(\mathrm{P}=0.001)$ and the subgroup with a count below that level $(\mathrm{P}<0.001)$, as well as in the subgroup with a pretreatment CD4 count of 200 cells per cubic millimeter or higher $(\mathrm{P}=0.004)$ and in the subgroup with a count below that level $(\mathrm{P}<0.001)$.

Figure 2 shows the proportions of subjects with an HIV-1 RNA level of less than 200 copies per milliliter and with a level below 50 copies per milliliter. At week 48, 74 percent of the subjects in the triplenucleoside group (95 percent confidence interval, 65 to 83 percent) had an HIV-1 RNA level below 200 copies per milliliter, and 61 percent ( 95 percent confidence interval, 50 to 72 percent) had an HIV-1 RNA level below 50 copies per milliliter; at the same time point, the corresponding percentages in the combined efavirenz groups were 89 percent ( 95 percent confidence interval, 85 to 93 percent) and 83 percent ( 95 percent confidence interval, 78 to 88 percent). A post hoc analysis designed to examine the durability of viral suppression in the subgroup of 923 subjects with at least one HIV-1 RNA value below 200 copies per milliliter during therapy demonstrated that the time to virologic failure was shorter in the triple-nucleoside group than in the combined efavirenz groups $(\mathrm{P}<0.001)$ (Fig. 3A). In an analysis including the 780 subjects with at least one HIV-1 RNA value below 50 copies per milliliter, a similar difference was suggested, but it was not statistically significant ( $\mathrm{P}=0.08)$ (Fig. $3 \mathrm{~B})$.

There were no significant differences between the groups with respect to the change in the CD4 cell count from base line ( $\mathrm{P}=0.58)$. At week 48 , the

Figure 1 (facing page). Time to Virologic Failure in the Study Population as a Whole (Panel A), among Subjects with an HIV-1 RNA Level below 100,000 Copies per Milliliter before Treatment (Panel B), and among Subjects with an HIV-1 RNA Level of 100,000 Copies per Milliliter or Higher before Treatment (Panel C).

$P$ values and $z$ scores were calculated with the log-rank test. 


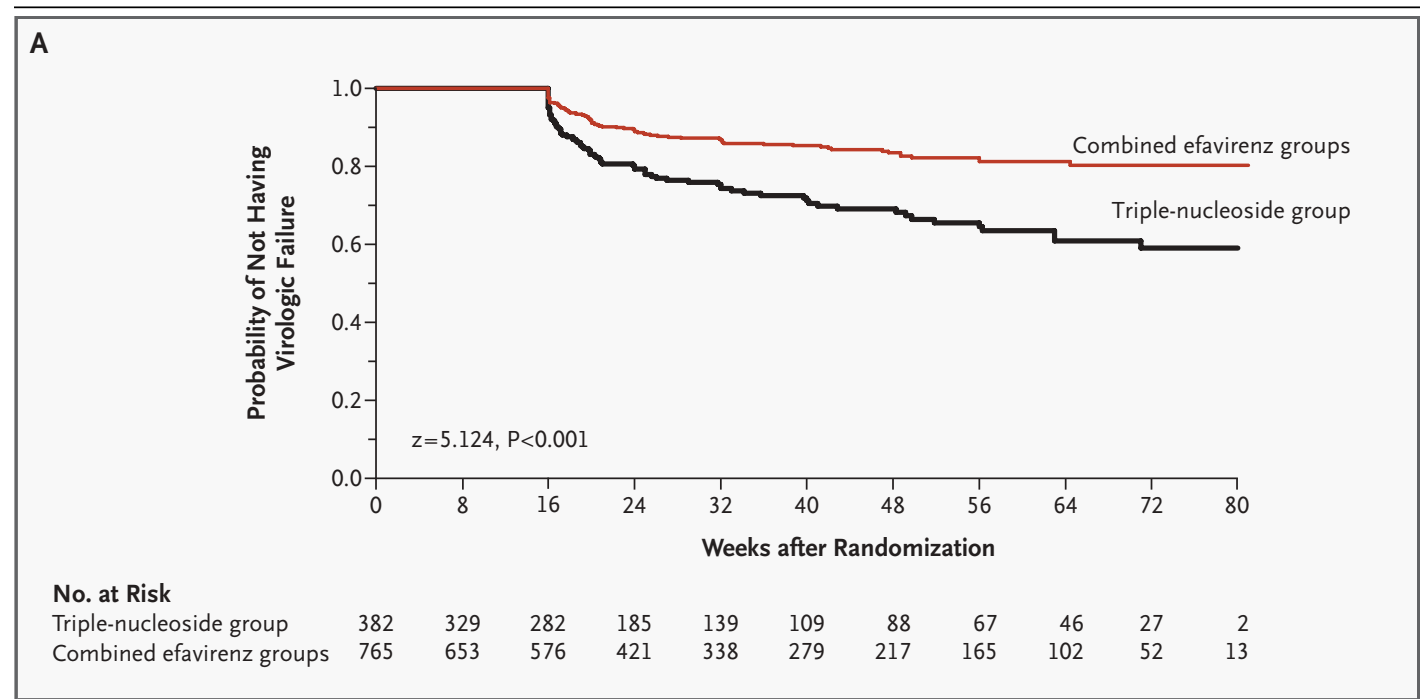

B

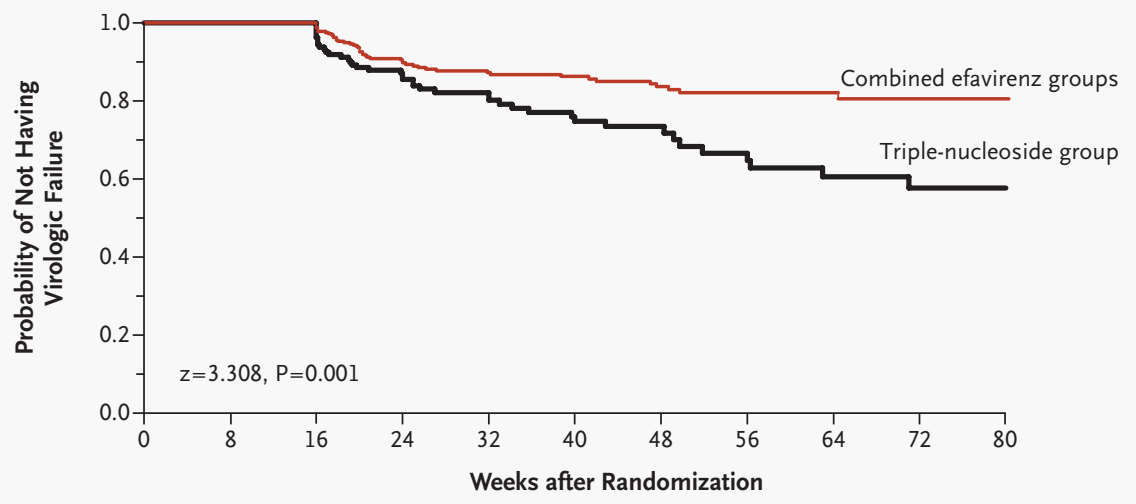

No. at Risk

$\begin{array}{lllllrrrrrrr}\text { Triple-nucleoside group } & 218 & 189 & 163 & 113 & 86 & 66 & 50 & 37 & 25 & 16 & 2\end{array}$

$\begin{array}{lllllllllllll}\text { Combined efavirenz groups } & 437 & 374 & 328 & 244 & 194 & 163 & 121 & 97 & 60 & 28 & 8\end{array}$

\section{$C$}

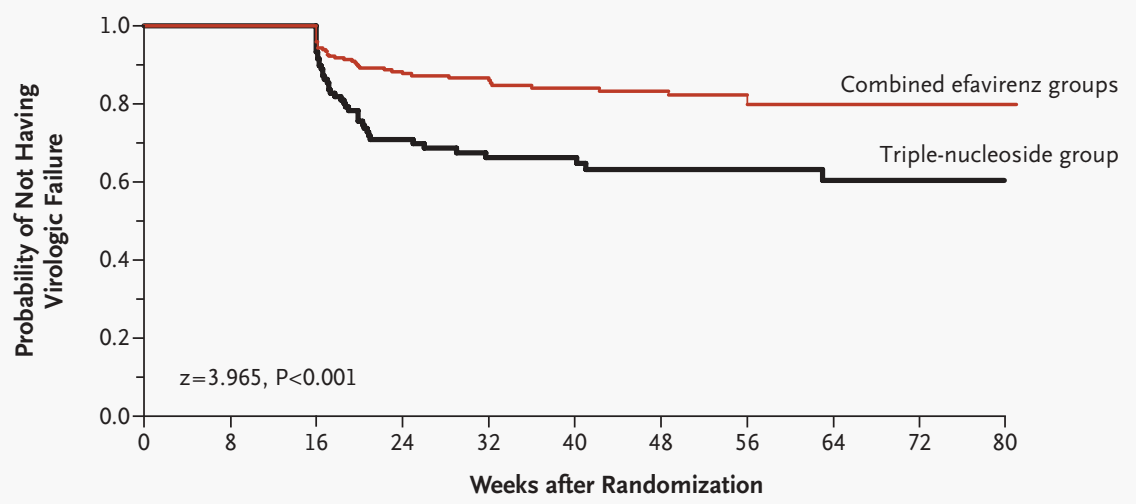

No. at Risk

$\begin{array}{llllllllllll}\text { Triple-nucleoside group } & 164 & 140 & 119 & 72 & 53 & 43 & 38 & 30 & 21 & 11 & 0\end{array}$

$\begin{array}{llllllllllll}\text { Combined efavirenz groups } & 328 & 279 & 248 & 177 & 144 & 116 & 96 & 68 & 42 & 24 & 5\end{array}$ 


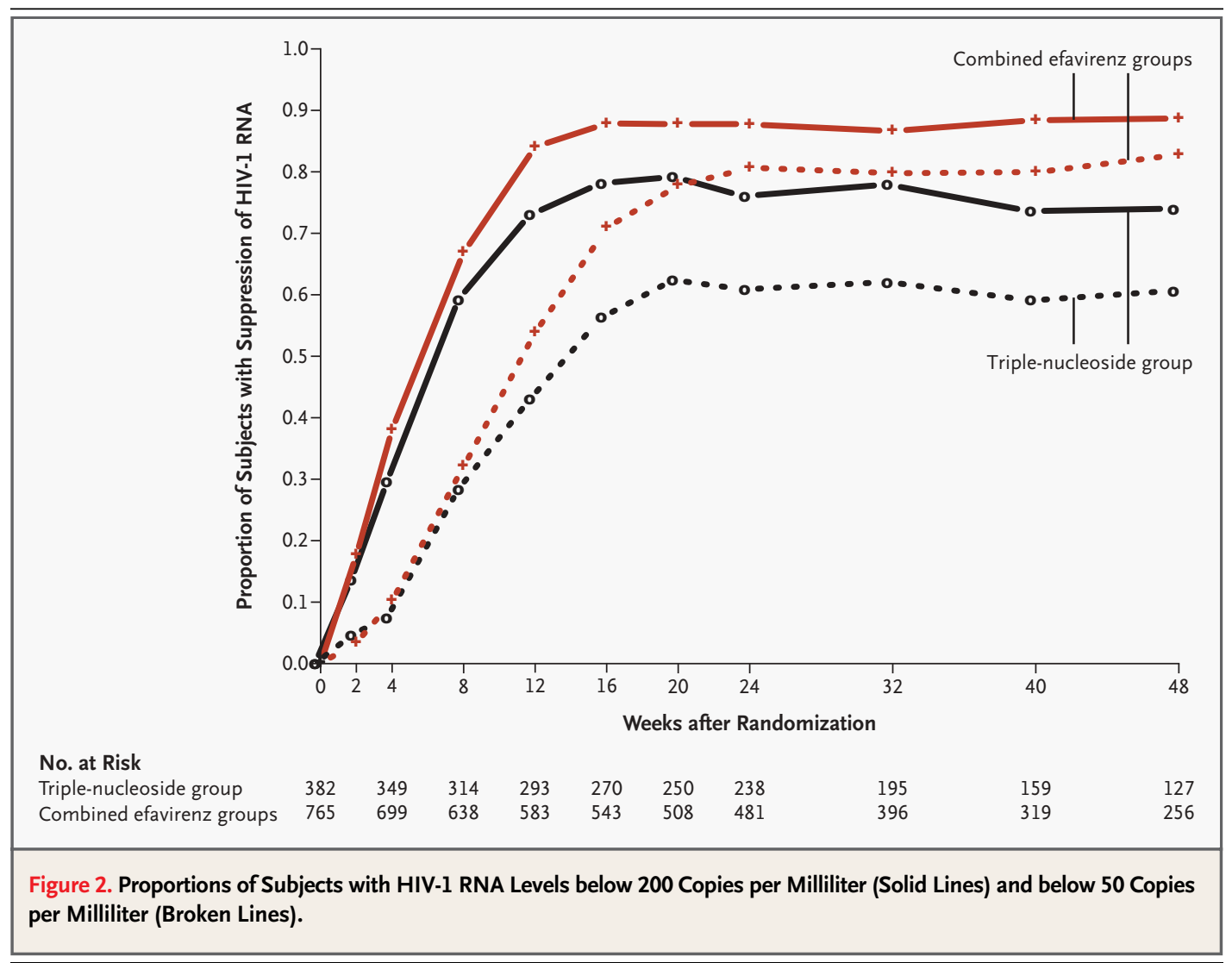

mean change in the triple-nucleoside group was an increase of 174 cells per cubic millimeter ( 95 percent confidence interval, 151 to 197) and the mean change in the combined efavirenz groups was an increase of 173 cells per cubic millimeter ( 95 percent confidence interval, 152 to 194).

\section{DRUG RESISTANCE}

Genotypic resistance testing was performed on the viral samples from 82 subjects in the triple-nucleoside group who had confirmed virologic failure (Table 2). At baseline, 78 of these subjects ( 95 percent) had wild-type virus, the virus from 3 subjects (4 percent) showed substitutions associated with resistance to reverse-transcriptase inhibitors, and no sample was available for 1 subject. At the time of confirmed virologic failure, 18 subjects (22 percent) had wild-type virus, 28 (34 percent) had only the M184V substitution in the reverse transcriptase (which confers resistance to lamivudine), 9 (11 percent) had the M184V substitution as well as other substitutions associated with reverse-transcriptase-inhibitor resistance, and 2 ( 2 percent) had substitutions associated with reverse-transcriptase- inhibitor resistance but did not have the M184V substitution. Sequencing was not attempted in 22 subjects (27 percent) who had HIV-1 RNA levels below 500 copies per milliliter, and virus from 3 subjects (4 percent) could not be sequenced. We do not report resistance information for the combined efavirenz groups, because double-blind study followup continues.

\section{ADHERENCE}

Of subjects reaching the time points, at least 94 percent reported adherence information. The median rate of self-reported adherence to the study regimen was 100 percent at weeks 4 (817 subjects), 12 (718 subjects), and 24 (561 subjects), without significant differences according to the treatment group $(\mathrm{P}=0.33, \mathrm{P}=0.74$, and $\mathrm{P}=0.69$, respectively). In all the treatment groups, subjects with adherence of less than 95 percent at week 12 (124 subjects, or 17 percent) had a higher rate of virologic failure than those with adherence of 95 percent or higher (594 subjects, or 83 percent) $(\mathrm{P}<0.001)$. In a post hoc analysis, the 195 subjects in the triple-nucleoside group who reported 100 percent adherence at 


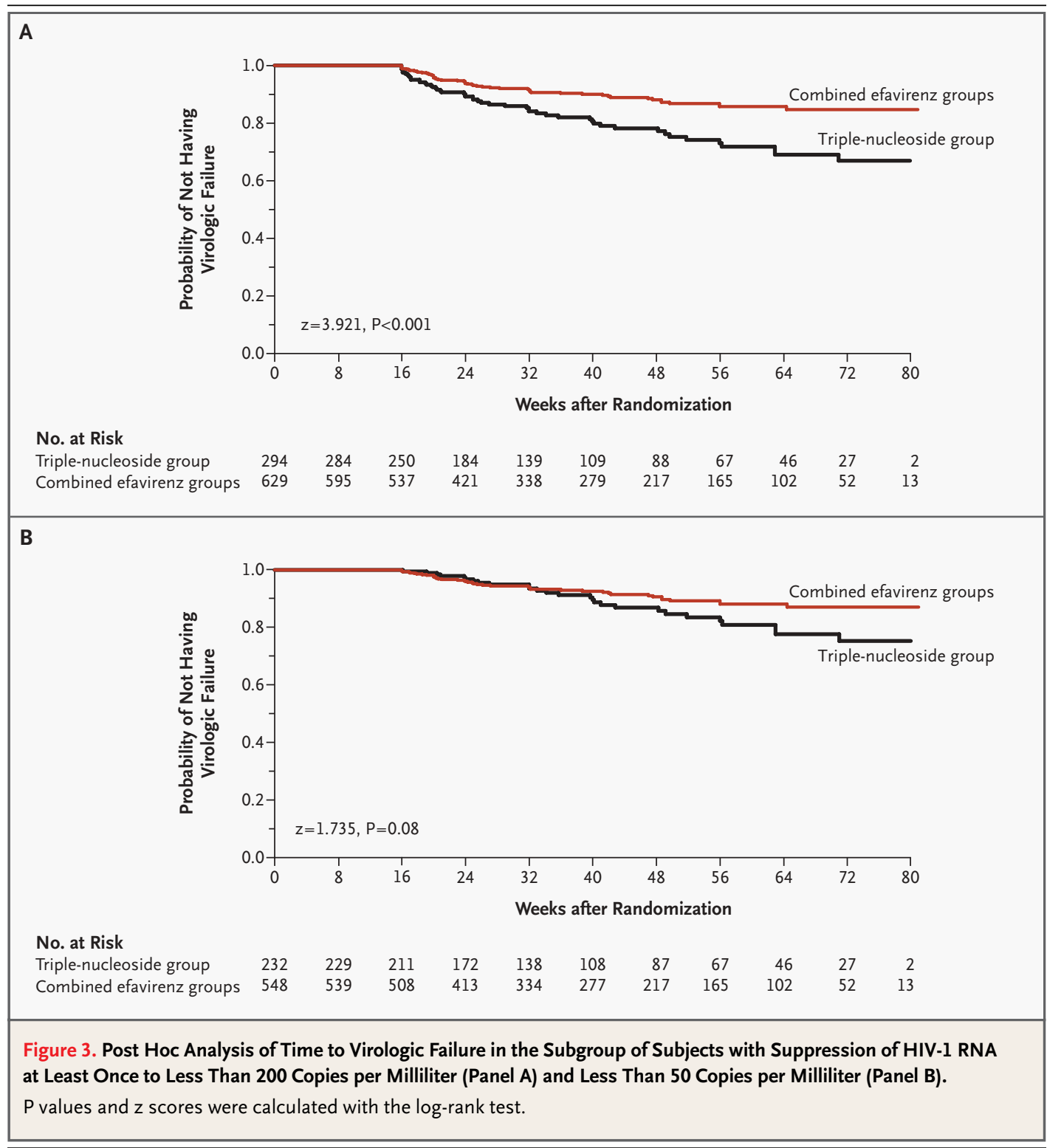

week 12 had a higher rate of virologic failure than the 382 subjects in the combined efavirenz groups with the same level of adherence $(\mathrm{P}<0.001)$.

\section{ADVERSE EVENTS}

Because of treatment-limiting toxic effects, 94 of the 1136 subjects who received zidovudine (8 percent) substituted stavudine for zidovudine, 40 of the 759 who received abacavir (5 percent) substituted didanosine for abacavir, and 46 of the 759 who received efavirenz ( 6 percent) substituted nevirapine for efavirenz. Suspected hypersensitivity reactions to study drugs occurred in 27 of the subjects in the triple-nucleoside group (7 percent) and 59 of the subjects in the combined efavirenz groups (8 percent). During treatment with the initial regimen, signs or symptoms of grade 3 toxic effects were observed in 37 of the subjects in the triple-nucleoside group (10 percent) and 95 of those in the combined efavirenz groups (13 percent); signs or symptoms of grade 4 effects were observed in 9 subjects ( 2 percent) and 17 subjects ( 2 percent), respectively. Also during treatment with the initial regimen, laboratory evidence of a grade 3 toxic effect was found in 70 of the subjects in the triple-nucleoside group (19 percent) and 132 of those in the combined efavi- 


\begin{tabular}{|c|c|}
\hline Variable & No. (\%) \\
\hline \multicolumn{2}{|l|}{ Baseline samples } \\
\hline Subjects with genotypic sequencing at baseline & $81(99)$ \\
\hline $\begin{array}{l}\text { Substitutions associated with resistance to reverse- } \\
\text { transcriptase inhibitors }\end{array}$ & $3(4)$ \\
\hline M41L & 2 \\
\hline V108I & 1 \\
\hline Wild-type virus & $78(95)$ \\
\hline Specimen not available & $1(1)$ \\
\hline \multicolumn{2}{|l|}{ Samples obtained at the time of virologic failure } \\
\hline $\begin{array}{l}\text { Subjects with genotypic sequencing at time of virologic } \\
\text { failure }\end{array}$ & $57(70)$ \\
\hline $\begin{array}{l}\text { Substitutions associated with resistance to reverse- } \\
\text { transcriptase inhibitors }\end{array}$ & $39(48)$ \\
\hline D67N, K70R, M184V, K103N, and V108I & 1 \\
\hline $\mathrm{D} 67 \mathrm{~N}, \mathrm{~K} 70 \mathrm{R}, \mathrm{M} 184 \mathrm{~V}$, and $\mathrm{K} 219 \mathrm{E}$ & 1 \\
\hline $\mathrm{D} 67 \mathrm{~N}, \mathrm{~K} 70 \mathrm{R}, \mathrm{M} 184 \mathrm{~V}$, and T215Y & 1 \\
\hline $\mathrm{D} 67 \mathrm{~N}$ and $\mathrm{M} 184 \mathrm{~V}$ & 3 \\
\hline D67N and T215Y & 2 \\
\hline M184V & 28 \\
\hline $\mathrm{M} 184 \mathrm{~V}$ and $\mathrm{T} 215 \mathrm{Y}$ & 2 \\
\hline $\mathrm{M} 184 \mathrm{~V}$ and $\mathrm{V} 108 \mathrm{I}$ & 1 \\
\hline Wild-type virus & $18(22)$ \\
\hline Sequencing not attempted (HIV-1 RNA level $<500$ copies $/ \mathrm{ml}$ ) & $22(27)$ \\
\hline Virus could not be sequenced & $3(4)$ \\
\hline
\end{tabular}

renz groups (17 percent); laboratory evidence of a grade 4 effect was found in 32 subjects ( 8 percent) and 78 subjects (10 percent), respectively.

\section{DISCUSSION}

In this randomized, double-blind, placebo-controlled study of initial antiretroviral regimens, we found the triple-nucleoside-analogue regimen of abacavir, zidovudine, and lamivudine to be virologically inferior to a regimen containing efavirenz and two or three nucleoside analogues. This difference was observed regardless of the pretreatment viral load or the CD4-cell-count stratum. Since the study population was diverse with representation from women, nonwhites, and intravenous drug users, these results are probably generalizable. Our findings suggest that an efavirenz-containing regimen is more potent than the triple-nucleoside regimen and support current guidelines that recommend efavirenz-based regimens among the preferred options for the initial treatment of HIV-1 infection. ${ }^{6,7}$

Our study allowed substitutions of drugs within the same classes in cases of treatment-limiting toxic effects, and we followed subjects regardless of whether they discontinued the study treatment. This intention-to-treat approach differs from analyses that consider missing data or switching drugs as treatment failures and could account for the higher rates of virologic suppression in our study than in other studies. ${ }^{11-13,18-20,29}$ We believe that our approach better reflects the original concept of an intention-to-treat analysis and approximates the current clinical management of antiretroviral therapy.

Previous studies showed that the triple-nucleoside regimen we used had efficacy similar to that of regimens containing indinavir or nelfinavir, with HIV-1 RNA levels of less than 400 copies per milliliter at week 48 in 51 to 66 percent of subjects overall. ${ }^{18-20}$ Another study, in which subjects were randomly assigned to receive stavudine-didanosine with indinavir, nevirapine, or lamivudine, showed similar rates of viral suppression at 48 weeks. ${ }^{13} \mathrm{Di}-$ rect comparison is the most appropriate way to assess the relative efficacy of treatment regimens. Our study suggests that although the triple-nucleoside regimen was successful in reducing viremia in many subjects, it was inferior to an efavirenz-containing regimen.

In a post hoc analysis performed in order to determine what to advise patients in whom viremia was suppressed by the triple-nucleoside regimen, we observed that subjects in the triple-nucleoside group who had at least one HIV-1 RNA value below 200 copies per milliliter had a higher rate of virologic failure than similar subjects in the efavirenz groups. Although post hoc analyses must be interpreted cautiously, this analysis suggests that the triple-nucleoside regimen may also be inferior to an efavirenz-containing regimen in maintaining viral suppression. The optimal management for patients with suppressed viremia during treatment with a triple-nucleoside regimen is uncertain.

Simplicity and convenience improve adherence to antiretroviral regimens and are critical for the maintenance of long-term virologic responses. ${ }^{29-32}$ The double-blind, placebo-controlled design of our study may have reduced the convenience of the regimens. Despite this possible effect, a median adherence rate of 100 percent was reported through week 24, without significant differences between 
the treatment groups. Among the subjects who reported 100 percent adherence, those who were taking the triple-nucleoside regimen had a higher rate of virologic failure than those in the combined efavirenz groups. An adherence rate of more than 95 percent was associated with a better virologic response in this study - a finding that is consistent with those of previous studies. ${ }^{31}$ Given the high adherence rates in both groups, differential adherence is unlikely to explain the differences in virologic response. However, because virologic failure occurred in patients with wild-type virus, selfreported adherence probably represents an overestimate of actual adherence.

Recent studies have documented an increasing prevalence of drug-resistant HIV-1 among previously untreated subjects with HIV-1 infection ${ }^{33,34}$ and, as a consequence, an increased risk of virologic failure of initial regimens. ${ }^{33}$ In the current study, substitutions in the viral genome were rare at base line, suggesting that preexisting drug resistance is unlikely to explain the higher rate of virologic failure in the triple-nucleoside group. At the time of virologic failure, viral isolates from about half the subjects in the triple-nucleoside group showed the M184V reverse-transcriptase substitution that is associated with lamivudine resistance - a finding that is also similar to those of previous studies. ${ }^{17,18}$ Although the resistance data from the combined efavirenz groups are not reported here so that we may maintain blinding, we would expect to find the M184V substitution, the K103N substitution associated with efavirenz resistance, or both in subjects with virologic failure. ${ }^{35}$

The incidence of grade 3 or grade 4 adverse events did not differ significantly between the treatment groups. Substitutions of alternative drugs because of treatment-limiting toxic effects, which were used in only 5 to 8 percent of the study subjects, re- flect current clinical practice and permitted us to focus on the classes of drugs rather than on specific agents.

Treatment of HIV-1 infection continues to evolve as new drugs and combinations are developed. Our results demonstrate the importance of assessing the relative efficacy of regimens through randomized, controlled clinical trials. In a diverse group of previously untreated HIV-1-infected patients, the triple-nucleoside combination of abacavir, zidovudine, and lamivudine was virologically inferior to an efavirenz-containing regimen as initial antiretroviral therapy. Clinicians should factor in the results of appropriately designed, comparative studies such as ours in selecting the optimal initial antiretroviral regimen for an individual patient.

Supported by grants (AI 38858 [AIDS Clinical Trials Group Central Grant], AI 01781, AI 25859, AI 25868, AI 25879, AI 25897, AI 25903, AI 25915, AI 25924, AI 27658, AI 27659, AI 27660, AI 27661, AI 27664, AI 27668, AI 27670, AI 27673, AI 27675, AI 27767, AI 28697, AI 32775, AI 32782, AI 34832, AI 38855, AI 39156, AI 42848, AI 42851, AI 46339, AI 46370, AI 46376, AI 46381, AI 46386, AI 50410, AI 51966, RR00044, RR00046, RR00047, RR00052, RR00096, RR00865, RR 02635, and subcontracts from grant AI 38858 with the Virology Support Laboratories at Brigham and Women's Hospital, the University of Alabama, the University of Colorado Health Sciences Center, the University of North Carolina, and Vanderbilt University) from the National Institute of Allergy and Infectious Diseases, National Institutes of Health.

Dr. Gulick reports having received consultation or lecture fees from Abbott, Bristol-Myers Squibb, GlaxoSmithKline, Roche, and Tibotec and grant support from Abbott, Merck, and Progenics; Dr. Shikuma consultation fees from GlaxoSmithKline; Dr. Squires consultation or lecture fees from Boehringer Ingelheim, Bristol-Myers Squibb, and GlaxoSmithKline, and grant support from Abbott, Merck, Gilead Sciences, and Tibotec; Dr. Murphy consultation fees and grant support from Bristol-Myers Squibb; Dr. Witt consultation fees from Abbott and grant support from Abbott, Gilead, and GlaxoSmithKline; Dr. Reichman grant support from Gilead, GlaxoSmithKline, and Triangle; and Dr. Kuritzkes consultation or lecture fees from Abbott, Bayer-Visible Genetics, Bristol-Myers Squibb, Gilead-Triangle, GlaxoSmithKline, Roche, Schering-Plough, Shire, OrthoBiotech, and ViroLogic and grant support from Boehringer Ingelheim, Bristol-Myers Squibb, GlaxoSmithKline, Hoffmann-LaRoche, Tanox, and Trimeris.

We are indebted to the patients who volunteered to participate in the study.

\section{APPENDIX}

In addition to the authors, other members of the ACTG A5095 protocol team included the following: C. Bick (Indiana University School of Medicine) and A. Boyle (University of California, Los Angeles), protocol laboratory technologists; V. Hughes (Weill Medical College of Cornell University), protocol field representative; A. Kmack and S. Oyola (Frontier Science and Technology Research Foundation), protocol data managers; A. Martinez (Division of AIDS, National Institute of Allergy and Infectious Disease), protocol pharmacist; M. Murphy and N. Webb (Frontier Science and Technology Research Foundation), laboratory data coordinators; V. Parillo (Community Constituency Group of the AIDS Clinical Trials Group), community representative; J. Schouten (University of Washington), Co-Investigator; D. Ferriman, M. Imperiale, M. McDonough, J. Stern, S. Storfer (Boehringer Ingelheim Roxane Laboratories); M. Giordano, K. Morrissey, J. Olson, M. Soccodato, M. Swingle (Bristol-Myers Squibb); C. Brothers, T. Scott, J. Tolson, and A. van Kempen (GlaxoSmithKline); laboratory personnel: J. Hicks (Brigham and Women's Hospital); R. D'Aquila, L. Sutton (Vanderbilt University); R. Young (University of Colorado Health Sciences Center); V. Johnson, J. Hazelwood, J. Parker (University of Alabama at Birmingham); S. Fiscus, L. Petch, T. Tribull (University of North Carolina, Chapel Hill); participating site staff: J. Kuruc, D. Currin, L. Dasnoit (University of North Carolina); D. McGregor (Northwestern University); T. Adeyemi (Cook County Hospital); H. Kessler (Rush-Presbyterian-St. Luke's Medical Center); S. Koletar, D. Gochnour, M. Hite (Ohio State University); M. Carlson, R. Mitsuyasu (UCLA School of Medicine); M. Guerrero (Harbor-UCLA Medical Center); C. Greisberger, R. Corales, C. Hurley (University of Rochester Medical Center); S. Marrero, O. Mendez, I. Torres (University of Puerto Rico); J. Richardson, 
J. Hernandez, S. Hamilton (Indiana University Hospital); M. Fischl, J. Castro, L. Ramirez (University of Miami); D. McMahon, S. Riddler (University of Pittsburgh); P. Kumar (Georgetown University Medical Center); S. Swindells (University of Nebraska); J. Meier (University of Iowa); H. Balfour, Jr. (University of Minnesota); P. Potter, J. Hoffman, F. Torriani (University of California, San Diego); M. Silberman, I. McClurkin, N. Thielman (Duke University Medical Center); D. Haas, J. Nicotera, J. Wang (Vanderbilt University); D. Johnson, W. Briggs, C. Funk (University of Southern California); J. Feinberg, D. Daria, C. Colegate (University of Cincinnati); T. Petersen, M. Scott (University of Texas, Southwestern Medical Center); P. Tebas, M. Rodriguez, K. Gray (Washington University); J. Scott, C. Basler, S. Johnson (University of Colorado Health Sciences Center); A. Sbrolla, C. Koziol, C. DeQuattro (Harvard University); J. Lennox (Emory University); K. Upton, J. Kilby (University of Alabama at Birmingham); T. Stroberg (Cornell University); J. Noel-Connor, M. Torres (Columbia University); J. Forcht, M. Vogler (New York University); T. Flanigan, K. Tashima, H. Sousa (The Miriam Hospital); A. Conrad, G. Gagliano, J. Baum (Case Western Reserve University); M. O'Connell, W. Wagner, D. Werner (University of Pennsylvania); A. Collier, B. Royer, L. Olin (University of Washington); S. Valle, S. Stoudt, D. Slamowitz (Stanford University); J. Frederick, S. Souza, D. Ogata-Arakaki (University of Hawaii); G. Costantini, R. D'Amico, D. Mildvan (Beth Israel Medical Center); D. Baker, A. Subramanian (Johns Hopkins University); S. Rauf, W. Silkowski (University of Texas, Galveston); D. Havlir, J. Lawrence, J. Volinski (San Francisco General Hospital); R. Pollard, S. Hulse, M. Schreiber (University of California, Davis).

REFERENCES

1. Gulick RM, Mellors JW, Havlir D, et al. Treatment with indinavir, zidovudine, and lamivudine in adults with human immunodeficiency virus infection and prior antiretroviral therapy. N Engl J Med 1997;337:734-9.

2. Hammer SM, Squires KE, Hughes MD, et al. A controlled trial of two nucleoside analogues plus indinavir in persons with human immunodeficiency virus infection and CD4 cell counts of 200 per cubic millimete or less. N Engl J Med 1997;337:725-33.

3. Cameron DW, Heath-Chiozzi M, Danner S, et al. Randomised placebo-controlled trial of ritonavir in advanced HIV-1 disease. Lancet 1998;351:543-9.

4. Mouton Y, Alfandari S, Valette M, et al Impact of protease inhibitors on AIDSdefining events and hospitalizations in 10 French AIDS reference centers. AIDS 1997; 11:F101-F105.

5. Palella FJ Jr, Delaney KM, Moorman AC et al. Declining morbidity and mortality among patients with advanced human immunodeficiency virus infection. $\mathrm{N}$ EnglJ Med 1998;338:853-60.

6. Panel on Clinical Practices for Treatment of HIV Infection. Guidelines for the use of antiretroviral agents in HIV-infected adults and adolescents. Rockville, Md.: AIDSinfo, November 10, 2003. (Accessed April 5, 2004 at http://www.aidsinfo.nih.gov/guidelines/ adult/archive/AA_111003.html.)

7. Yeni PG, Hammer SM, Carpenter CC, et al. Antiretroviral treatment for adult HIV infection in 2002: updated recommendations of the International AIDS Society-USA Panel. JAMA 2002;288:222-35. [Erratum, JAMA 2003;289:32.]

8. Carr A, Samaras K, Burton S, et al. A syndrome of peripheral lipodystrophy, hyperlipidaemia and insulin resistance in patients receiving HIV protease inhibitors. AIDS 1998;12:F51-F58.

9. Walli R, Herfort O, Michl GM, et al Treatment with protease inhibitors associated with peripheral insulin resistance and impaired oral glucose tolerance in HIV-1 infected patients. AIDS 1998;12:F167-F173. 10. Mulligan K, Grunfeld C, Tai VW, et al. Hyperlipidemia and insulin resistance are induced by protease inhibitors independent of changes in body composition in patients with HIV-1 infection. J Acquir Immune Defic Syndr 2000;23:35-43.

11. Staszewski S, Morales-Ramirez J, Tashima KT, et al. Efavirenz plus zidovudine and lamivudine, efavirenz plus indinavir, and indinavir plus zidovudine and lamivudine in the treatment of HIV-1 infection in adults. N Engl J Med 1999;341:1865-73.

12. Podzamczer D, Ferrer E, Consiglio E, et al. A randomized clinical trial comparing nelfinavir or nevirapine associated to zidovudine/lamivudine in HIV-infected naive patients (the Combine Study). Antivir Ther 2002;7:81-90.

13. van Leeuwen R, Katlama C, Murphy RL et al. A randomized trial to study first-line combination therapy with or without a protease inhibitor in HIV-1-infected patients. AIDS 2003;17:987-99.

14. Trotta MP, Ammassari A, Cozzi-Lepri A et al. Adherence to highly active antiretroviral therapy is better in patients receiving nonnucleoside reverse transcriptase inhibitorcontaining regimens than in those receiving protease inhibitor-containing regimens. AIDS 2003;17:1099-102.

15. Henry K, Wallace RJ, Bellman PC, et al. Twice-daily triple nucleoside intensification treatment with lamivudine-zidovudine plus abacavir sustains suppression of human immunodeficiency virus type 1 : results of the TARGET Study. J Infect Dis 2001;183:571-8. 16. Kirkland LR, Fischl MA, Tashima KT, et al. Response to lamivudine-zidovudine plus abacavir twice daily in antiretroviral-naive, incarcerated patients with HIV infection taking directly observed treatment. Clin Infect Dis 2002;34:511-8.

17. Ait-Khaled M, Rakik A, Griffin P, et al. Mutations in HIV-1 reverse transcriptase during therapy with abacavir, lamivudine and zidovudine in HIV-1-infected adults with no prior antiretroviral therapy. Antivir Ther 2002;7:43-51.

18. Staszewski S, Keiser P, Montaner J, et al Abacavir-lamivudine-zidovudine vs indinavir-lamivudine-zidovudine in antiretroviralnaive HIV-infected adults: a randomized equivalence trial. JAMA 2001;285:1155-63. [Erratum, JAMA 2001;285:2858.]
19. Vibhagool A, Cahn P, Schechter M, et al. Abacavir/combivir ( $\mathrm{ABC} / \mathrm{COM})$ is comparable to indinavir/combivir in HIV-1 infected antiretroviral therapy naïve adults: preliminary results of a 48-week open label study (CNA3014). In: Final programme and abstracts of the 1st IAS Conference on HIV Pathogenesis and Treatment, Buenos Aires, Argentina, July 8-11, 2001:102. abstract.

20. Matheron S, Descamps D, Boue F, et al. Triple nucleoside combination zidovudine/ lamivudine/abacavir versus zidovudine/ lamivudine/nelfinavir as first-line therapy in HIV-1-infected adults: a randomized trial. Antivir Ther 2003;8:163-71.

21. Kalbfleisch JD, Prentice RL. The statistical analysis of failure time data. New York: John Wiley, 1980.

22. Wei LJ, Johnson WE. Combining dependent tests with incomplete repeated measurements. Biometrika 1985;72:359-64.

23. Mantel N, Haenszel W. Statistical aspects of the analysis of data from retrospective studies of disease. J Natl Cancer Inst 1959;22:719-48.

24. O'Brien PC, Fleming TR. A multiple testing procedure for clinical trials. Biometrics 1979;35:549-56.

25. Lan KKG, DeMets DL. Discrete sequential boundaries for clinical trials. Biometrika 1983;70:659-63.

26. Peto R, Pike MC, Armitage P, et al. Design and analysis of randomized clinical trials requiring prolonged observation of each patient. I. Introduction and design. BrJ Cancer 1976;34:585-612.

27. Jennison C, Turnbull BW. Group sequential methods with applications to clinical trials. Boca Raton, Fla.: Chapman \& Hall/ CRC, 2000.

28. Pocock SJ. Group sequential methods in the design and analysis of clinical trials. Biometrika 1977;64:191-9.

29. BartlettJA, DeMasi R, Quinn J, Moxham C, Rousseau F. Overview of the effectiveness of triple combination therapy in antiretroviral-naïve HIV-1 infected adults. AIDS 2001; 15:1369-77.

30. Bangsberg DR, Hecht FM, Charlebois $\mathrm{ED}$, et al. Adherence to protease inhibitors, HIV-1 viral load, and development of drug 
resistance in an indigent population. AIDS 2000;14:357-66.

31. Paterson DL, Swindells S, Mohr J, et al. Adherence to protease inhibitor therapy and outcomes in patients with HIV infection. Ann Intern Med 2000;133:21-30. [Erratum, Ann Intern Med 2002;136:253.]

32. Trotta MP, Ammassari A, Melzi S, et al. Treatment-related factors and highly active antiretroviral therapy adherence. J Acquir sistance among recently infected persons. Immune Defic Syndr 2002;31:Suppl 3: JAMA 2002;288:181-8.

S128-S131. 35. Bacheler LT, Anton ED, Kudish P, et al. 33. Little SJ, Holte S, Routy J-P, et al. Antiret- Human immunodeficiency virus type $1 \mathrm{mu}$ roviral-drug resistance among patients re- tations selected in patients failing efavirenz cently infected with HIV. N Engl J Med 2002; combination therapy. Antimicrob Agents 347:385-94.

Chemother 2000;44:2475-84.

34. Grant RM, Hecht FM, Warmerdam M, Copyright (c) 2004 Massachusetts Medical Society. 